of expanding the scope of Latin American studies in British universities, and it was hoped to announce a practical first step towards this end in the autumn.

\section{Medical Research Council Vision Research Unit}

THE Medical Research Council have announced that, on the assumption of financial responsibility for the major part of the work of their Ophthalmo. logical Research Unit by the University of London from August 1, the Unit's Visual Research Division will be reconstituted as a separate Council Unit under the direction of Dr. H. J. A. Dartnall, at present head of the Council's Visual Research Division. It will be known as the Vision Research Unit and will continue to be housed in the Institute of Ophthalmology, Judd Street, London, W.C.l.

\section{Supply of Science Teachers}

A REPORT entitled The Supply of Science Teachers in England and Wales by the Joint Committee for Science and Education (Pp. 19. London: Joint Committee for Science and Education, 15 Half Moon Street, 1962. 1s.) states that, immediately, there is need for an increase of between 28,000 and 34,000 over the present number of graduate science teachers in schools, technical colleges, training colleges and universities, which stands to-day at about 20,600 . In addition, the report states that an increase of 12,000 18,000 non-graduate specialists in science teaching will be needed in schools. The shortage of science teachers is seen to be one part of the general teacher shortage, but many reasons are given for regarding it as a separate and specially urgent problem. The present and future supply of mathematics teachers is an equally grave problem. The whole education system, and not only science teaching, will suffer without an adequate supply of mathematics teachers. But, in the Committee's view, the supply of mathematics and of science teachers presents two distinct problems. The sooner this is accepted, "the sooner will policies be forthcoming which are adequate to the solution of both problems". There is a general awareness of the increasingly urgent need for more scientists and technologists in industry and the public services. This report emphasizes the need to consider not only the training of these specialists but also the training of non-specialists. "We need not only more specialists. We need a common culture which includes more science. To achieve this we must foresee science being taught to all children throughout their school lives."

\section{Science Laboratories in Grammar Schools}

Provision and Maintenance of Laboratories in Grammar Schools (1961) is the title of a report compiled from 762 answers to a questionnaire sent to grammar schools in England and Wales (Pp. 16. London: John Murray. Published for the Science Masters' Association, 1962. 2s. net). The object of the survey, the third of its kind, was to find out whether laboratory facilities in schools were satisfactory and, if not, in what respects they were unsatisfactory. The report compares existing facilities, first, with the standards recommended by the Ministry of Education and, secondly, with the standards recommended by the Industrial Fund for the Advancement of Scientific Education in Schools. Compared with 1959, there has been an increase from 45 to 55 per cent in the number of local education authority schools which have, according to Ministry of Education standards, adequate laboratories. Local education authority schools, however, still lag behind direct grant and independent schools. More local education authority schools now employ one or more laboratory technicians, but only 8 per cent of these schools employ a sufficient number of technicians. In many cases the local authority makes no provision for such assistance, and the report stresses the importance of adequate technical assistance in the teaching of science. Laboratory finance is expressed as the amount spent per annum per pupil taking sciencethe minimum sum regarded as adequate being $12 \mathrm{~s} .6 \mathrm{~d}$. Local education authority schools for boys spend on the average $13 s .6 d$., compared with $12 s$. 3d. in 1959 . The report points out that 50 per cent of these schools spend less than $12 s$. $6 d$. per annum per child, which is not adequate. Girls' schools, particularly, have inadequate facilities for teaching seience, as well as suffering from an acute shortage of science teachers. Mixed schools, in general, lie between boys' and girls' schools, while the laboratory facilities in comprehensive and bilateral schools vary considerably.

\section{Bulletin of the Royal Society International Scientific Information Services}

The Royal Society has established a special library for the publications of the International Council of Scientific Unions, the International Scientific Unions, Commissions, Special Committees and Permanent Services, as well as of certain other publications such as those of the United Nations Educational, Scientific and Cultural Organization in the Arid Zone, Humid Tropics and Marine Sciences. With this library as a basis, it is planned to provide an information service to facilitate use in the United Kingdom of the international contacts of the Royal Society. The first issue of the Bulletin of the Royal Society International Scientific Information Services, which it is proposed will be published regularly, has become available (1, No. 1; July 1962. Pp. 80. London: The Royal Society, 1962). It contains complete lists of the holdings of the Society, arranged under the International Council and under the different International Unions or other bodies responsible for publication. Future issues will keep the catalogue up to date, and in his preface Sir Patrick Linstead expresses the hope that the Bulletin will keep scientists in touch with international developments. It is also proposed to include occasional articles on international scientific affairs and notes on exchanges, visits, grants and similar matters. The first issue is well produced and admirably designed for its task of making these scientific publications more widely known.

\section{The British Journal for the History of Science}

SHORTLY after the British Society for the History of Science was formed in 1947 it produced a Bulletin which, owing to the stringency of the times, was virtually a broad-sheet. Later, by arrangement, the Bulletin was published as a supplement to the Annals of Science, with Dr. N. H. de V. Heathcote as a connecting link between both journals, being editor of one and on the editorial board of the other. Yet even this arrangement had its difficulties, as papers read to the Society could not be published in extenso. Now, however, a major step forward has been taken with the issue of The British Journal for the History of Scienc?, 1, Part 1, No. 1; June 1962. Pp. 95. (Published twice annually. Ravensmoad, Keston, Kent: The British Society for the History of Science. 1962. 